Bryn Mawr College

Scholarship, Research, and Creative Work at Bryn Mawr College

Graduate School of Social Work and Social

Graduate School of Social Work and Social

Research Faculty Research and Scholarship

Research

2003

\title{
Substance Abuse and Welfare Policy at the New Century
}

Jim Baumohl

Bryn Mawr College, jbaumohl@brynmawr.edu

Richard Speiglman

James A. Swartz

Roland Stahl

Let us know how access to this document benefits you.

Follow this and additional works at: http://repository.brynmawr.edu/gsswsr_pubs

Part of the Social Work Commons

\section{Custom Citation}

Baumohl, Jim, Richard Speiglman, James A. Swartz, and Roland Stahl. "Substance Abuse and Welfare Policy at the New Century." Contemporary Drug Problems 30, no. 1/2 (2003): 501-537.

This paper is posted at Scholarship, Research, and Creative Work at Bryn Mawr College. http://repository.brynmawr.edu/gsswsr_pubs/51

For more information, please contact repository@brynmawr.edu. 


\title{
Substance abuse and welfare policy at the new century
}

\author{
BY JIM BAUMOHL, RICHARD SPEIGLMAN, \\ JAMES A. SWARTZ, AND ROLAND STAHL
}

Drawing on findings from the SSI Study and other research, this paper takes up various policy questions fundamental to any welfare program for substance abusers. The paper considers the place of disability benefits in the U.S. system of categorical aid and the problems raised by substance abuse for the disability category. It discusses the desirable objectives of a welfare program for substance abusers and the various mechanisms by which they might be achieved. And finally, it considers how any new program might be positioned in the context of categorical aid and American federalism.

KEY WORDS: Welfare policy, substance abuse, disability, representative payment, mandatory treatment, supported work.

This essay concludes the set of papers gathered in this issue of Contemporary Drug Problems to report findings from the "SSI Study," a two-year longitudinal inquiry conducted in nine sites in five states with panels that included nearly 1,800 disabled Supplemental Security Income (SSI) beneficiaries who initially qualified for aid on the basis of drug addiction 
or alcoholism (DA\&A). The principal aim of the study was to appraise the results of a 1996 federal policy reform that eliminated DA\&A as a disabling impairment. Drawing on findings from this and other research, the present paper examines policy options that might govern the intersection of substance abuse and the "means-tested" income maintenance programs known colloquially as "welfare."

Substance abusers have had a long relationship with the American welfare system. From the Gilded Age into the 1960 s, big cities typically managed impoverished hard drinkers and later morphine and heroin addicts with occasional spells of incarceration and periodic detention in state or county hospitals, poorhouses, or work farms. Many cities provided a pittance in non-institutional relief often doled out as chits for transportation, meals, and the once plentiful single-room lodgings in skid row and tenderloin districts (Baumohl and Tracy, 1994; Blumberg, Shipley, and Barsky, 1978; Wiseman, 1971). By the 1970s, however, both the federal government and the various states for the most part avoided institutionalizing substance abusers for long-term treatment (Baumohl and Jaffe, 2001). Indeed, at the end of the 1960s, California and New York, moving rapidly toward an emphasis on community care, began to use the federal-state welfare program Aid to the Disabled (ATD, 1950-1974) to support indigent alcoholics and addicts in local settings much as it provided a non-institutional subsistence to poor persons with severe mental illness. In 1974 SSI folded together under complete federal funding and administration ATD, Aid to the Blind, and Old Age Assistance, welfare programs that provided federal funds linked to a state match. SSI aimed to provide a better standard of living for members of these groups and to relieve states, counties, and kin of much of the economic burden of their support (Hunt and Baumohl, a, this issue). 
The Social Security Administration's Drug Addiction \& Alcoholism (DA\&A) program was implemented along with SSI. Until Congress terminated it in 1996, the program intended to provide material support, financial oversight, access to treatment and monitoring of progress, and vocational rehabilitation for people unable to work for at least 12 months due to their drinking or other drug use. But these comprehensive intentions notwithstanding, the DA\&A program was starved for resources until its 1994 reform-by which time it was politically moribund. Even with new resources to better promote and monitor treatment, the program had neither control of treatment slots nor sure access to job training or placement for beneficiaries. Further, too few resources was not the program's only problem. Always susceptible to political attack due to the ambiguous moral status of addiction, the program achieved fatal notoriety in the early 1990 s as the result of technical problems that made caseload size and the behavior of recipients very difficult to control (Hunt and Baumohl, a, this issue).

With the demise of the DA\&A program, substance abusers still need an accommodating welfare system of some sort. As Campbell, Baumohl, and Hunt (this issue) demonstrate, even in the tightest labor market in American history, very few former DA\&A beneficiaries, sober or otherwise, found sustaining employment in the two years following the program's termination. Left to fend for themselves, it seems that few long-term substance abusers with little previous labor-market attachment will ever work regularly. The days of easily available unskilled work, particularly of the sort that could accommodate erratic sobriety, are long behind us in the United States.

Moreover, in the absence of decently paid unskilled work, housing status is very sensitive to welfare retrenchment. As Campbell et al. (this issue) show, in the two years after termination of the DA\&A program, fewer than one-quarter of former beneficiaries who were not collecting some form of 
income maintenance earned sufficient income to make even a one-room apartment affordable. Norris and her colleagues (this issue) find that rates of literal homelessness and residential doubling-up increased dramatically among those who did not requalify for SSI.

Such material deprivation did not usually translate into functional deterioration (see Guydish, Ponath et al., this issue; Speiglman, Norris et al., this issue; Swartz and Martinovich, this issue). On the whole, SSI Study respondents seem to have been fairly resilient. Most had coped with a lifetime of poverty, and having lost SSI after a year or a few years, they went back to scuffling as they had before. Buffering support from family and friends, unmeasured by the SSI Study instrument, almost certainly contributed mightily to their functional stability post-termination. In the SSI Study's supplemental semistructured interviews (see Swartz, Tonkin, and Baumohl, this issue) we find numerous examples of disqualified beneficiaries who continued to live where they had lived before-in a basement flat in a family-owned triplex, for example-but who stopped paying rent. Here, the forbearing property owner, often a widowed mother or a better-off sibling, took a significant financial hit. Campbell et al. (this issue) describe various ways in which family members, especially, softened the blow of lost benefits.

This shifting of the so-called "burden of dependency" is an important political question. All cutbacks in income maintenance involve some renunciation or reorganization of public responsibility. The costs of welfare can be shifted within the public sector (among different levels of government, for example, as the creation of SSI intended) and, as a result, among taxpayers (as when the financing of welfare moves from federal income taxes to local property and/or sales taxes). When public support is partially or completely withdrawn, cutbacks can "privatize" the burden, as in residential doubling-up, or shift the burden to the budgets of various 
public and nonprofit agencies charged with feeding hungry people or housing those without homes.

We see all of these forms of cost-shifting in connection with the change in DA\&A policy. SSI is federally financed, but when former beneficiaries turn instead to local and state welfare programs, costs move accordingly. Where local and state welfare programs don't exist, food banks and homeless shelters take more weight. When eligibility contracts, impositions on friends and family become potentially greater. ${ }^{2}$ We have no data that allow us to specify the magnitude of any such effects of ending the DA\&A program, but the matter of what cost to whom must necessarily figure in any consideration of what to do next.

In our judgment, there are two basic policy choices. The first is to leave indigent substance abusers to their friends, kin, and the country's overwhelmed and largely ineffectual local apparatuses for serving homeless people and jailing misdemeanants. This amounts to business as usual, which like welfare itself represents a state of affairs resented by beneficiaries, taxpayers, and policymakers alike. The second is to reinstate in some fashion a system of material benefits and treatment that offers the hope of a moderately independent and decent life. We think the former is a more likely outcome, but we much prefer the latter. Although we have no compelling evidence on the issue, we believe that in the long run constructive support and intervention will considerably benefit poor substance abusers, their parents, siblings, and children, and the communities in which they live.

With such issues in mind, this paper develops as follows. Immediately below, we consider the place of disability benefits in the American system of categorical aid. This alerts us to important problems that will plague any attempt to support substance abusers under the rubric of disability. Next, we consider the desirable objectives of a welfare program for substance abusers and various mechanisms by which to 
achieve them. Finally, we take up how to position any potential program in the context of categorical aid and American federalism, particularly in view of the Personal Responsibility and Work Opportunity Reconciliation Act, the watershed federal welfare-reform legislation of 1996, and the erosion of General Assistance, the generic name for the shrinking number of state and local welfare programs that support persons who do not qualify for federal aid. In this connection, we examine two programs, one public and one private, that make different contributions to the policy solution we favor.

\section{Categorical aid and disability benefits}

All societies face what Deborah Stone (1984) dubbed "the distributive dilemma." This is the intractable problem of managing the tension between two principal systems of distribution, one based on work and the other on need. As Stone (1984:18) observes, the primacy of work is preserved only when need-based distribution is "understood to be extraordinary, outside the normal rules" of distribution. Thus societies invent rules to define exceptions to the expectation that people provide for themselves through work. ${ }^{3}$ These exceptions are organized as administrative categories. In the incomemaintenance system of the United States, as in other contemporary welfare states, the politico-administrative construction of disability defines such an excepted category. Disability is not the only administrative category to serve this purpose, but along with others derived mainly from age, it authorizes publicly supported partial or total, short- or long-term tickets of leave from the labor force.

Since these categories arise from the imperative to make need-based support extraordinary, taken together they must not comprise a viable alternative to work for too many people. The definition of "too many" is of course a matter of historical circumstance and politics; but to have effect, the 
categories must be administered with meaningful restrictions. From this consideration arises the principle of "less eligibility" that has guided Anglo-American relief practices since the British Poor Law of 1834. As a policy term, less eligibility means that relief should be "less eligible" (that is, less attractive) as a choice than even the most poorly paid and objectionable work. By this logic, relief should be stingy and administered under deterrent conditions. The low value of American welfare benefits, the active stigmatization of relief, and the labyrinthine processes of becoming and remaining eligible for it attest to less eligibility's enduring relevance.

But the principle of less eligibility raises a problem for a system that would take need seriously. To truly provide for needy people, relief must be adequate; it must provide a benefit that promotes a healthy standard of living by the society's benchmark. In theory, however, this removes relief's deterrent power by making its benefits equivalent to or better than those of a bad job-minus, of course, the unpleasant necessity of working. ${ }^{4}$ In the case of disability, this contradiction is particularly salient because disability benefits are intended to promote health and a return to work whenever possible. Even so, the concern with deterrence prevails, and American federal disability benefits are extremely modest: The SSI cash benefit for a single, sighted individual in 2002 was only $\$ 545$ per month. ${ }^{5}$

The logic of low benefits is easy to see if we consider the position of disability benefits in the structure of American income maintenance and the problem of validating disability.

In the American system of categorical aid, officially hale and sane, non-elderly indigent adults without children in their care qualify for no cash assistance whatsoever in most jurisdictions. For this large portion of the non-working poor, there is no welfare system to speak of, a principal reason why homeless shelters are stocked disproportionately with such "uncategorized" people (Greenberg and Baumohl, 1996). 
Such a state of affairs forces uncategorized poor people to seek a categorical niche in their pursuit of aid-and because it is difficult to invent custodial parenthood or suddenly become 65 years old, the disability category is the only one that offers much hope. Indeed, there is a well-documented historical correlation between rising disability claims and prolonged periods of high unemployment (Stone, 1984). Moreover, in recent decades the prosecution of disability claims has been supported by a legal advocacy sector whose strategy has been to spread wide the categorical boundaries, thus to approach a guaranteed annual income through the back door (see Davis, 1993). In short, the structural position of the disability category makes it attractive to extremely poor people who fit nowhere else in the welfare system; and the higher the disability benefit relative to others, the more attractive it becomes and the more persistent the claimants. Low benefits, strict standards of impairment, and careful validation of claims aim to minimize this effect.

For purposes of public administration, a definition of disability is technical in that it provides rules to determine when such claims are relevant and valid. The technical validation of disability is a serious problem for the categorical system. As Hunt and Baumohl discuss at length ( $a$, this issue), the DA\&A program found it extremely difficult to defend its technical judgments against administrative appeal and broader legal assault because substance abuse is a disability examiner's nightmare: a condition with ambiguous definition, severity, prognosis, and consequences. In this respect, it is more like myalgic encephalomyelitis ("chronic fatigue immune dysfunction syndrome") than liver cirrhosis. Uncoupled from more clear-cut impairments that can result from it, the role of substance abuse in disabling a person for work for at least a year (Social Security's strict temporal standard) is extremely difficult to discern consistently across cases. This makes the disability-determination process liable to a high percentage of reversals on appeal and to more-encompassing 
legal attack. In this sector, at least, the categorical distinction between the disabled and the able is subject to collapse. The category is not amenable to conservative fiscal administration and is apt to get "out of control" (see U.S. House of Representatives, 1994).

This is what happened to the DA\&A program, which, in spite of its modest benefits, grew from fewer than 10,000 beneficiaries in the early 1980 s to well over 200,000 at termination (Hunt and Baumohl, a, this issue). Indeed, the program was still growing rapidly when new eligibility was halted by March 1996 legislation. Although 1994 reforms limited lifetime DA\&A eligibility to three years, thus making the program's costs more predictable, the program's potential caseload size, though unknowable, was presumably much greater than any level that it achieved.

In sum, in a categorical structure of aid, the disability category is vulnerable to rapid expansion, particularly in sectors where technical validation of disability is problematic. Thus any disability program that includes substance abuse per se as an eligible work impairment must be ready to absorb tremendous initial growth, particularly if its benefits are adequate rather than miserly, or merely more adequate than other alternatives, as was the case with SSI in comparison with state and local welfare benefits, where available. Time limits and caseload caps are the obvious mechanisms by which to manage this problem, but probably at the expense of considerable unmet need.

Substance abuse also challenges the legitimating function of the disability category, which is to communicate culturally and politically acceptable reasons for joining the need-based system of distribution. As Hunt and Baumohl ( $a$, this issue) discuss, substance abuse is culturally ambiguous even when it rises to a stricter standard of "dependence" or "addiction": a condition officially designated a "disease" but nonetheless widely believed to be precipitated by repeated bad judgment 
and often illegal behavior. While in professional circles the term "behavioral health problem" may have supplanted the more colorful Victorian term "vice disease," its euphemistic nature is not lost on many members of Congress or state legislatures. Considered as impairment that can disable people for employment and thus exempt them from a market society's closest kin to a sacred obligation, substance abuse is tainted by its origins in elected risk of a disreputable sort. Such impairment is not amenable to thoroughgoing "medicalization" and is perennially vulnerable to delegitimation, as recent history attests.

Given this, we believe that to be initially feasible and to avoid political doom in the longer run, any program that provides welfare to substance abusers must directly face issues of behavior control. More specifically, it must return some politically acceptable percentage of its beneficiaries to work; it must demonstrably benefit the general well-being of its recipients or at least do them no harm; and it must avoid scandal. We turn now to what might be expected from a welfare program for substance abusers.

\section{Welfare and behavior control}

Welfare programs have long attempted to change the behavior of their recipients. Therapeutic intervention has sometimes been required as an accompaniment of aid so that beneficiaries might see the advantages of "rational living," as charity organizer Edward T. Devine (1904:19) put it with the earnest condescension of his class and time. State-sponsored Mothers' Pension programs, implemented widely beginning in the 1910s, and the federal Aid to Dependent Children program (later, Aid to Families with Dependent Children, or AFDC), from its inception in 1935 until well into the 1960 s, conditioned initial and continuing eligibility on acceptable parental behavior (see Gordon, 1994; Abramovitz, 1988). The Per- 
sonal Responsibility and Work Opportunity Reconciliation Act of 1996, which replaced AFDC with Temporary Assistance for Needy Families, permits states wide latitude to condition assistance on the behavior of parents and children. Finally, in-kind assistance (as opposed to cash) has long been used selectively or across the board to protect welfare recipients from their putative ignorance, poor judgment, or bad habits (Hunt and Baumohl, b, this issue). Indeed, in November 2002, San Francisco voters agreed to transform local welfare benefits for homeless people into housing and services under the slogan "care not cash" (San Francisco Chronicle, November 7, 2002).

Although initiated during a period when welfare paternalism was in retreat, the SSI DA\&A program drew nonetheless on a variety of behavior-control measures. To remain eligible for benefits, recipients had to participate in treatment when "appropriate and available" and permit a third party-a "representative payee"- to receive their checks and, in theory, dole out their money with a sense of fiduciary responsibility. The program's architects expected that with these requirements and other help and guidance, substantial numbers of beneficiaries would return to work and forgo welfare.

In our view, the goals of the DA\&A program were unobjectionable. It makes sense to keep substance abusers housed and fed and to promote their participation in treatment and their return to work. There are various ways to accomplish these goals, however. Below, we address such variations briefly and distill the lessons we can from what research findings there are. In the last section of this paper, "Positioning a New Drug Addiction and Alcoholism Program," we discuss how these separate pieces might fit together and under what auspices.

Cash vs. in- Advocates of in-kind assistance argue that the cash benefits kind benefits of something like the DA\&A program interfere with the treatment process, harming their recipients by giving them money 
to drink and use illegal drugs. Transforming benefits into vouchers for housing, food, and other necessities, so the argument goes, would mitigate this "enabling" feature of public provision (Hunt and Baumohl, b, this issue).

There is ample and persuasive evidence that substance-abusing recipients of cash benefits acquire alcohol and other drugs (Speiglman, Norris et al., this issue; Hunt and Baumohl, b, this issue; Catalano and McConnell, 1999; Rosenheck and Frisman, 1996; Shaner, Eckman et al., 1995). But this is not to say very much. Even in the confines of hospitals, jails, and prisons, alcohol and other drugs have long been part of the institutional economy (Baumohl and Tracy, 1994). Access to cash, in other words, is not a singular route to the acquisition of intoxicants, nor does curtailing the availability of cash necessarily curb their use. What we really want to know is if one form or another of welfare benefits promotes the goals of reduced substance use, an improved quality of life, and the achievement of gainful employment. While there is no clear answer to this question, there is evidence that claims for the salutary effect of in-kind assistance are dubious.

Using a sample of male military veterans addicted to cocaine and diagnosed with schizophrenia, and relying on repeated weekly urine tests for cocaine, self-reported psychiatric symptoms, and validated hospitalizations, Shaner, Eckman et al. (1995) found that cocaine use, hospitalizations, and psychiatric symptomatology peaked together during the first week of each month and then subsided. The authors inferred that these convergent peaks were associated with the receipt of disability payments at the beginning of the month. On the other hand, in a study of homeless veterans, Rosenheck and Frisman (1996) found that after controlling for level of income, substance-abusing subjects who received cash benefits reported fewer days of alcohol and other drug use than did those who did not receive them. 
Subsequently, Catalano and McConnell (1999) analyzed psychiatric emergency room admissions in San Francisco and found an $8 \%$ increase at the beginning of the month. However, they also found this pattern to persist after the end of the DA\&A program, which had many beneficiaries in San Francisco. This caused them to posit a more general "check effect" than one limited to federal disability benefits.

An analysis of SSI Study data that does not appear in the present collection of papers supports their conclusion. Using data from the three SSI Study sites that validated selfreported illegal drug use with urinalysis, Swartz, Hsieh, and Baumohl (in press) found that cocaine use peaked during the first week of the month even among former DA\&A beneficiaries who had little or no reported income. As heroin use did not vary in this manner, they interpreted their findings to mean that after the first of the month, when money from a variety of sources flows most freely, even the most destitute cocaine users can tap members of their personal networks for loans or gifts of cash or drugs-and that bingeing (common among cocaine users but not among heroin addicts) often is the result. Bingeing and treating others to a drunk have long been associated with payday drinking in taverns and saloons, of course, even among those who could least afford it (Lender and Martin, 1987).

We conclude that there are many sources for the cash that intensifies cocaine use and probably drinking at the beginning of the month. We do not think that in-kind assistance for identified substance abusers would make any real difference in the phenomenon. Even transforming all public aid into inkind assistance probably would not reduce the problem significantly. There are too many sources of cash, too many possibilities for barter, and the critical exchanges are too thoroughly woven into daily social relations for the matter to be addressed this way. As cash benefits have important practical and symbolic value to their recipients that in-kind assis- 
tance does not (see Hunt and Baumohl, b, this issue), we favor cash benefits.

Still, cash payments to substance abusers have a very important political liability, for however complex the economic realities at the intersection of poverty and addiction, cash benefits give the impression of providing the means for drinking and illegal drug use. Indeed, the best argument against them is political: For public aid programs, cash benefits are a constant source of potential scandal and delegitimation.

Representative payment
There is little good research on the impact of representative payment on the alcohol and other drug use of welfare beneficiaries, though a number of studies have found that clinicians working with addicted or psychiatrically impaired individuals support the use of representative payment to control substance use (e.g., Hanrahan, Luchins et al., 2002; Rosen, Rosenheck et al., 2002). Studying a large sample of homeless people with concomitant psychiatric and substance use disorders who were enrolled in a federal demonstration of integrated services, Rosenheck, Lam, and Randolph (1997) found that representative payment was not associated with any improved outcome except fewer days of homelessness (no small matter). Swartz et al. (in press) did not find that continued representative payment (for those requalifying for SSI) made any difference in whether a former DA\&A beneficiary used heroin or cocaine in the two years following termination of the program. However, this dichotomous measure of drug use neglects possible important benefits apart from outright abstinence. Hunt and Baumohl's (b, this issue) analysis of narrative data from the SSI Study's semistructured interviews found that a substantial majority of respondents liked having a payee and believed that payees who took a genuine interest in them, whether family members or social service workers, helped them "take care of business" in a responsible way. As respondents reported, this often meant serving as a brake on alcohol and other drug consumption. 
Thus, while we have no reason to believe that representative payment effectively promotes abstinence from drinking and drug taking (but see Shaner, Roberts et al., 1997), there is testimonial evidence that it slows users down and ensures that their basic needs are met. On this basis, we favor representative payment. However, contrary to the bias toward organizational payees adopted by the Social Security Administration in 1994, we follow Hunt and Baumohl's observation (b, this issue) that organizational representatives don't necessarily make better payees than family members. Most important, we think, is that the payee role be clearly defined and communicated, and that the benefit program oversee the payee-beneficiary relationship effectively. Given the cost of such oversight, and with other compelling matters before it, the Social Security DA\&A program never paid much attention to these things.

Mandatory treatment
Research mainly on court-ordered populations shows that treatment mandates keep their subjects in treatment for longer periods than those free of such coercion and that outcomes improve with the length of exposure to treatment (Hiller, Knight et al., 1998). In the SSI Study, Swartz, Campbell et al. (this issue) found that the DA\&A treatment mandate also kept people in treatment, though they had no measure of its effectiveness. Moreover, and to their surprise, Hunt and Baumohl (b, this issue) found that an overwhelming majority of the DA\&A recipients who participated in the study's semistructured interviews thought the mandate was a good idea, even if they resented the requirement at first. While many based their opinions on their favorable perceptions of treatment's utility, others saw the requirement more abstractly as a just quid pro $q u o$, an expression of a tacit social contract.

Without claiming any miraculous effects for it, or suggesting that consumers universally approve of it, we think mandatory participation in "appropriate and available" treatment should be a principle of public assistance for substance abusers. Quite apart from any rehabilitative contributions, we believe 
that a treatment mandate of some kind is widely understood to be a fair demand of those unable to work, albeit a demand more likely to be lodged against members of a disreputable group. ${ }^{6}$ In any event, we believe that mandatory treatment is a political requirement of any feasible welfare program for substance abusers.

Promoting Throughout its history, Social Security's DA\&A program had work a dismal record of returning beneficiaries to work (Hunt and Baumohl, a, this issue), and, as we have discussed, the end of the program did not act as the hoped-for catalyst in this respect. Briefly, the problem is as follows.

First, although its beneficiary group got somewhat younger during the 1990 s, the SSI DA\&A program supported mainly middle-aged, long-term substance abusers with few vocational skills, poor records of educational achievement, spotty work histories, and many years of neglected health. This population has very limited human capital and probably a low ceiling on its potential development. Moreover, its members often show the signs of hard miles: They have rough manners, missing teeth, prison tattoos, and so forth. Whatever technical skills they lack, they do not meet the public well, which makes many low-level service jobs unavailable to them. Decently paid "information economy" jobs are well beyond their reach and will remain so regardless of training investments. Regular unskilled work at something above the minimum wage and with health benefits is the best outcome for which most can hope.

But such hope is mocked by the unskilled-labor surplus in many regional job markets, the lack of transportation to get to what jobs exist, and the rarity of benefits in the secondary labor market. Moreover, the federal minimum wage of $\$ 5.15$ per hour has reached a historic low against the cost of housing, representing less than half the estimated "housing wage" in most metropolitan areas (National Low Income Housing Coalition, 2002). Even if available to them, the work for 
which members of this population qualify will not keep them housed and fed. Under such circumstances, they are wisest to use their benefits as supplements to unreported, sometimes criminal, often off-book wages, as did some SSI Study respondents (Campbell et al., this issue; see also Edin and Lein, 1997, and Rank, 1994, on single mothers on welfare). This is the inexorable logic of poverty, whatever the rules of public assistance.

This quandary has not gone unremarked or unattended over the years. Some of New York City's welfare-assisted heroin addicts participated in the well-known Wildcat Service Corporation supported work experiment in the early 1970s. Operated by the Vera Institute of Justice, Wildcat achieved notable success in stabilizing the lives of addicts while they were in subsidized public and non-profit sector jobs supported by social services. Based on the Wildcat model, a Ford Foundation collaboration with the federal government created the Manpower Demonstration and Research Corporation (MDRC), which developed supported work programs in several cities for AFDC mothers, ex-addicts, ex-offenders, and unemployed youths. These operated through 1979. Over half of the recovering addicts in MDRC programs were welfare recipients, some of them SSI beneficiaries (Hollister, Kemper, and Maynard, 1984; MDRC, 1980). More recently, other non-profits have pursued somewhat similar visions. The Doe Fund, a New York City organization, has fielded highly publicized work-based residential programs for recently abstinent former substance abusers in Manhattan, Brooklyn, Jersey City, and Philadelphia. The formal substance-abuse treatment sector has shown growing interest in "integrating substance abuse treatment and vocational services," to invoke the title of a recent federally published volume (Young, 2000). All over the country, the employment provisions of the Personal Responsibility and Work Opportunity Reconciliation Act have set off a scramble to promote the employment of heads of households on welfare, a small percentage of whom are 
substance abusers (see Pollack, Danziger et al., 2002; Dasinger, Speiglman, and Norris, 2002; Norris, Speiglman, and Dasinger, 2002; California Institute for Mental Health, 2000). The Social Security Administration has launched a new initiative, the "Ticket to Work" program, that intends to make the notoriously resistant vocational rehabilitation sector more responsive to seriously impaired consumers, though its impact on substance abusers remains to be seen now that the DA\&A program is defunct.

But to the extent that welfare-to-work programs have been evaluated over the years, all have run up against the same problem: The market does not provide enough regular, sufficiently paid employment. While young, healthy welfare recipients (with transportation and child care when necessary) can become competitive for existing work, many are unable to keep it (Dasinger et al., 2002; Schram and Soss, 2001; Loprest, 1999). Absent non-market alternatives, most people like those in the former SSI DA\&A program probably cannot get and keep employment. Although the Wildcat and MDRC sites served a much younger client group (average age about 31 at Wildcat and 28 for the other sites), rates of unsubsidized employment ebbed sharply after separation from supported work, and while the programs had some positive effects, they had no significant impact on drug use (Skidmore, 1984; MDRC, 1980).

The foregoing history has at least two important implications. First, the promotion of work for poor, chronically unemployed substance abusers should acknowledge extreme differences in likely employment outcomes related to age, impairment, and human capital more generally-whatever the labor market conditions. Viewed from a different angle, welfare policy should acknowledge the same difference and be prepared to tolerate long-term assistance for some portion of this population. Second, to successfully promote work, especially for those who have reached middle age with very limited human capital, long-term non-market alternatives must 
be developed. And to be successful where simple make-work is not, these must be more than disciplinary measures whose main value lies in demonstrating the contemporary relevance of the principle of less eligibility. They must be able to give otherwise dull and dirty work some meaning and value (Currie, 1993; Baumoh1, 1992a, 1992b; Hopper, 1992).

\section{Positioning a new drug addiction and alcoholism program}

Formidable financial and technical hurdles face any new public assistance dispensation for substance abusers, but the cultural status of addiction is the biggest political obstacle. In spite of two centuries of repeated claims that addiction is a disease (Levine, 1978), and more recently that it is similar to other chronic diseases (White, 1998), the idea that addiction is rooted in repeated bad choices remains widely compelling. The importance accorded to intention, on the one hand, and the acknowledged power of compromising medical, social, and genetic factors, on the other, continue to roil a debate that has no end in sight (Committee on Addictions of the Group for the Advancement of Psychiatry, 2002). As a result, addicts remain unpopular political allies, even in disability rights circles. It is hardly surprising that a recent textbook on the disability rights movement avoids the subject of addiction altogether, even in its consideration of the movement's problematic heterogeneity (see Fleischer and Zames, 2001:200-215). Indeed, the Americans with Disabilities Act (ADA), the foremost legislative achievement of the disability rights movement, specifically excludes "psychoactive substance abuse [sic] disorders resulting from current illegal use of drugs." Alcoholism, while categorized for purposes of the ADA as a mental disability along with conditions like schizophrenia and bipolar disorder, is nonetheless treated in special ways by statute and case law that limit its legally disabling status, particularly concerning the distinction between 
alcoholism and dangerous or otherwise reprehensible alcoholism-related behavior (Orwick, 2001).

Even in the treatment realm ambiguity arises because after addiction sets in some people stop using alcohol and other drugs without any treatment at all (so-called "natural recovery") (Sobell, Ellingstad, and Sobell, 2000). The SSI Study's semistructured interviews yielded a number of such accounts. And despite the clamor of the recovery community, it also seems that some unknown number of formerly dependent individuals revert to moderate drinking or "recreational use of drugs" and continue to avoid dependence (Sobell and Sobell, 1995; Waldorf, Reinarman, and Murphy, 1991; Roizen, 1987; Biernacki, 1986). Nor is the widely sounded pragmatic argument that "treatment works" without important caveats. The most recent national study of the effectiveness of drug treatment, the Drug Abuse Treatment Outcome Studies (DATOS), found that treatment for drug use was most effective for those who remained in treatment at least 90 days and for those who had the lowest problem severities at intake (Simpson, Joe, and Broome, 2002). However, treatment dropout was relatively common, with $30 \%$ of the sample leaving before reaching the 90-day effectiveness threshold. Relapse and re-enrollment in treatment following the index admission were also common. These findings conform to past studies of treatment retention, relapse, and outcomes. They illustrate that while treatment can have a large, beneficial impact for many, treatment adherence and retention remain significant problems, especially for those with the most severe addictions and associated problems (e.g., mental health issues, lack of social support, criminality; see McLellan, Lewis et al., 2000). This is the very group of former beneficiaries that seems to be having the most difficulty following termination of the SSI DA\&A program (Swartz and Martinovich, this issue; Swartz, Martinovich, and Goldstein, this issue).

The political landscape is thus clouded by the many socially undesirable consequences of addiction, notably fears for pub- 
lic safety, the observations that treatment is only moderately successful and that at least some people can quit or cut down on their own, and by the disreputable risk-taking associated with pre-addiction drinking and using. Those who would make policy flow logically from a disease model of addiction find it very difficult to be fully convincing.

We have no solutions to offer for the lack of political will, especially in the current environment of renewed deficits and fiscal retrenchment. However, we have some ideas about what a welfare program for substance abusers might look like-ideally and otherwise-and we have some sense of the problems that should be anticipated and the tradeoffs that should be weighed. ${ }^{8}$

We begin with the assumptions that any welfare program for substance abusers must fit somehow within a categorical system of aid, and that for therapeutic and political reasons, representative payment and mandatory treatment are minimum requirements. We start here because these assumptions come with considerable expenses attached: The administrative separation of substance abusers from other poor people, the recruitment and supervision of representative payees, and the provision of required treatment and the monitoring of compliance all entail significant costs. If we complicated this picture by adding mechanisms of vocational rehabilitation and longterm alternatives to market employment, and if we insisted on a benefit adequate to a decent standard of living, costs would rise dramatically, and the demand for the program's benefits would likely be extraordinary. There are ways to contain eligibility and implement half measures, and we will discuss some of them below, but our first point is that it will be expensive to mount any program that might return a significant percentage of its beneficiaries to work (market-based or otherwise), provide a decent subsistence to the unemployable, and be administered with sufficient care to avoid scandal. While the program would certainly reduce other social costs connected with the population it would support (incarceration 
and the use of public shelters, for example), we have no way to estimate these plausibly, and we suspect that the offset would be modest (see, for example, Culhane, Metraux, and Hadley, 2002).

The costs of a fully developed program suggest that the federal government would be the only feasible major underwriter. Given the 1996 decentralization of welfare policy in the form of block grants made to states under Temporary Assistance for Needy Families (TANF), only a similar model would seem viable unless a DA\&A-like program were reestablished in the Social Security Administration (SSA). However, given the technical difficulties of the DA\&A program and the political beating the SSA took in connection with it, that agency has no interest in bringing it back. Moreover, as Hunt and Baumohl (a, this issue) note, while the SSA is renowned for getting the right check to the right person at the right time, it is not well equipped to run or oversee a welfare program that relies on significant measures of behavior control. Thus, while we have serious reservations about the administrative capacities of local governments, and while we worry about the basic terms of equity across jurisdictions under a decentralized policy regime, we think that the only remotely possible federal mechanism would be a block grant program-perhaps a new dimension of the Substance Abuse Prevention and Treatment grant-that would encourage states to develop a comprehensive connection between welfare, treatment, and work. (Many states would also need to reform their Medicaid plans to support treatment adequately.)

Whatever level of government provides the largest share of funding, we favor a separate category of public assistance for indigent substance abusers. This would prevent some problems peculiar to a disability program like Social Security's, particularly those of assessing the comparability of impairments (see Hunt and Baumohl, a, this issue) and the assumption of long-term disability. The eligibility rules of a freestanding program could be tailored to substance abuse, 
and the controversial term "disability" need never be invoked. Still, such a separate category would exist within a non-universal system of aid, and, especially if the benefits were useful, the pressure on the category's boundary would remain intense. Also, the validation problems would remain untouched. Utilization of standard diagnostic criteria such as those specified by the DSM-IV-TR (Text-Revision) might be substituted for the SSA's confusing standard, but every validation mechanism that relies on self-report is subject to manipulation by the savvy applicant, particularly if assisted by an experienced advocate. More objective measures of drug use such as urine testing and hair analysis present their own problems: Neither of these methods detects alcohol use (the clearance rate is too fast for most applications of urine testing), nor can drug use, which is what these tests measure, be equated with abuse or dependence (Harrison, 1997).

A separate substance-abuse category would be linked to a disability category only by cases where the principal impairment is something other than substance abuse (e.g., a major psychiatric disorder or advanced liver cirrhosis). An irony of the DA\&A program's demise is that roughly 80,000 former beneficiaries continued to receive benefits by virtue of an impairment other than drug addiction or alcoholism but were no longer subject to the requirements of representative payment and mandatory treatment. No one knows how many of these people had continuing substance abuse problems, but any new welfare program for substance abusers should include this group in its service plan, if only for outreach and screening purposes." Similarly, such a program could be a specialized resource for TANF programs and perhaps for the child welfare and criminal justice systems.

Having catalogued such issues, it is now useful to examine a program that addresses some of them. The state of Washington operates a General Assistance (GA) program that provides disability benefits to indigent people whose impairments predict less than the one-year term of disability 
required by SSI. ${ }^{10}$ In 1987 , worried about malingering and the "enabling" features of the cash benefit (just over $\$ 300$ per month), the Washington legislature foreshadowed congressional action on the federal DA\&A program when it eliminated "alcoholics and drug addicts" from GA. At the same time, however, the state's Alcoholism and Drug Addiction Treatment and Support Act created a new category of aid known by the statute's acronym, ADATSA. The goal of ADATSA is to take unemployable addicts and alcoholics and make them employable.

To be eligible for ADATSA, a person must meet a strict financial means test and be unemployable for 90 days due to "chemical dependency" as determined by a certified addiction professional. The applicant must have been drinking or using other drugs during the previous 90 days and in addition have a history of alcohol- or drug-related arrests, have lost jobs due to substance use, or be pregnant or parenting. These criteria are designed mainly to exclude individuals with no demonstrable history of serious substance abuse. Still, the program can consider as an exception anyone needing treatment who meets the financial means test and the criterion of unemployability.

A chemical-dependency counselor decides the appropriate type and level of treatment, which at present determines the cash value of the grant. Those in residential settings get $\$ 38$ per month for "clothing and personal incidentals," or what beneficiaries call "Cokes and smokes." Both outpatient and residential treatment are supported by state funds and by the federal Substance Abuse Prevention and Treatment block grant. The counties administer "outpatient ADATSA" through sub-contracts with local providers. Outpatients get $\$ 339$ per month, but a treatment agency staff member, who acts like a Social Security representative payee, regulates its use. The agency pays the client's rent and other bills and provides a little cash for "Cokes and smokes." The $\$ 38$ per month 
allowance for participants in residential treatment will be discontinued next year, and ADATSA will thus provide what amounts to only in-kind assistance. ADATSA includes methadone maintenance treatment, supported by either state medical benefits or Medicaid, but capacity is limited and there is no cash benefit.

ADATSA is also a funding source for residential treatment for TANF and SSI beneficiaries. (Outpatient care and methadone maintenance treatment for these individuals are billable to Medicaid.) These programs refer beneficiaries with declared or suspected substance abuse. The referring program pays the public assistance benefit and ADATSA supports the cost of residential care. Similarly, Washington's GA program refers recipients who have a qualifying impairment other than substance abuse but are nonetheless in need of substance abuse treatment. State administrators refer to this colloquially as "secondary ADATSA."

As Hunt and Baumohl (a, this issue) observe, Congress limited DA\&A eligibility to three years in order to control caseload size. This was necessitated by the Social Security Administration's cumbersome and ineffective continuing-disability review process, which likely allowed thousands of DA\&A recipients to remain on the rolls long after they were medically (if not realistically) able to work. Until July 2002, ADATSA participation was limited to 180 days in a two-year period. However, as the average stay in the program was only 90 days, this cap was eliminated. Currently the duration of any cash benefit is set at the discretion of the treatment agency and limited by county policy. For the most part, however, the relatively short participation period of ADATSA clients is the result of the systematic case review built into the clinical process at the point of service.

ADATSA's location of initial and continuing eligibility decisions in the hands of treatment personnel gives these counselors a great deal of authority. Often the counselors also 
monitor mandates imposed by the criminal courts and the child welfare system. This is extremely efficient from an administrative point of view, and it combines various sources of leverage in order to promote treatment adherence. But it likely creates the challenging worker-client tensions discussed by Hunt and Baumohl (b, this issue), and some clients may feel a potentially counterproductive sense of coercion (discussed in the context of severe mental illness by Elbogen, Swanson, and Swartz, 2002). Although agencies must have grievance procedures in place and state regional administrators arbitrate unresolved problems, ADATSA's is a system that relies heavily on clinical judgment and discretion rather than on the procedural formalism that characterizes the Social Security system.

The process of regular case review also allows ADATSA to help the state's GA program manage its caseload in relation to SSI. An ADATSA client whose substance abuse is moderated by treatment but who still has some other significant impairment is referred back to GA for help in applying for SSI and for advocacy services that persist through the level of appeal to an administrative law judge. The ADATSA treatment process thus helps identify chronically debilitated alcoholics and drug addicts who may still qualify for SSI on the basis of another impairment. This saves GA substantial future sums, of course. Additionally, the state recoups from the applicant's retroactive SSI benefits the amount of GA benefits paid while the SSI claim was pending."

In sum, ADATSA addresses many of the political and technical problems faced by a welfare program for substance abusers:

- By creating a separate category of assistance and by making treatment the principal program benefit, it avoids most of the problems that plague defense of the disability boundary. 
- By fusing treatment and material benefits administered by representative payment it meets immediate material needs, imposes behavior controls, and minimizes the likelihood of scandal.

- By serving as a clearinghouse and funding source for substance abuse treatment within the public assistance apparatus, it integrates treatment within the welfare system.

- By providing substance abuse treatment and advocacy services that address eligibility requirements of the federal disability system, it conserves the state's GA resources.

This much said, ADATSA has serious limitations. The program has the capacity to serve only an estimated $20 \%$ of those in need of treatment and likely to be eligible. The state reimburses residential treatment at only $\$ 67$ per day from the Substance Abuse Prevention and Treatment block grant, and the state supports only 1,600 treatment slots of all kinds at any time. The cash benefit for outpatients is far from adequate. Perhaps most significant, although the system promotes vocational support and has had some success returning participants to work, it has no capacity to develop the kinds of long-term nonmarket employment opportunities that many ADATSA graduates almost certainly need.

The solution to this problem does not lie within the purview of any treatment system, nor are there any useful public-sector rehabilitation models on which to draw for inspiration. However, the Doe Fund, a private, non-profit organization, has established a program called Ready, Willing \& Able (RWA) that is worth examining briefly by way of conclusion. We are interested in the program's approach rather than in its effectiveness, which remains unproved. ${ }^{12}$

RWA is a long-term residential program for men that mixes therapeutic community and behavioral approaches to recovery with daily paid work by residents, the wages from which are substantially matched by the program in a grant made at graduation. Designed initially for homeless men, it is now 
more broadly oriented to ex-offenders and others whose lives are at loose ends but who are "ready, willing, and able" to work. It is not a treatment program per se, but it requires regular random drug tests of residents and staff (conducted on site). Most residents are African American or Hispanic and have considerable histories of substance abuse and limited human capital. Typically, residents are in their thirties. The program likes to keep residents for at least nine months, although the optimal length of stay is set at 18 months. ${ }^{13}$ RWA's facilities vary in size, with the Manhattan (Harlem) facility accommodating about 200 , the Brooklyn and Philadelphia programs only 70, and Jersey City just 59 .

For our purposes, RWA's approach to work is of most interest. Simply put, in the program's worldview work both structures life and lends it dignity. As long-term substance abusers are chronically short of discipline and self-respect, hard work is deemed the best remedy. But RWA is no contemporary equivalent of the 19th-century charity woodyard, an infamous institution in which tramps, merely to show they weren't work shy, cut wood or broke stones in return for a flop (Ringenbach, 1973). The labor of most RWA residents is in some respects equally dull and sometimes physically demanding (cleaning sidewalks and clearing trash and brush in parks, for example), but its performance is embedded in an egalitarian system of social relationships intended to produce intense solidarity among participants-including the supervisors, most of whom have come up through the ranks. Moreover, the performance is set in highly visible public places, thus to demonstrate a contribution to the common good, and the men wear distinctive blue uniforms that set them apart from, say, orange-clad jail inmates who might perform similar labor. This is a work and service ethic honed to a fine point. Symbolically, it represents both individual transformation and the transformation of a putatively parasitic class of citizen. 
RWA does provide some literacy and minor computer training, but the program doesn't impart "hard skills"; it inculcates "life skills," which include a disciplined attitude toward work and other responsibilities, particularly those concerning family. Its product is "character," as cultural conservatives might put it. Successful completion involves achieving private employment, and RWA works hard to cultivate corporate sponsors who will hire its graduates. In this last respect, the program is not very innovative in that it does not develop new jobs. It is only one more example of a market-conforming vocational rehabilitation effort that makes one set of former outcasts more competitive than are others for a limited number of existing jobs.

Of much more interest to us are the public-service jobs done by program residents. Here we glimpse the possibility of nonmarket alternatives that could be put to long-term use were the volume of employment sufficient (a major stumbling block given the American political economy; see Weir, 1992; Hopper and Baumohl, 1994). For example, in Philadelphia about one-third of RWA's residents are employed by contract with the city in highly visible areas of Fairmount Park doing cleanup and brush clearance that the park's relatively small unionized labor force can't manage. This is the sort of work routinely performed by legions of unskilled men in the decades before Social Security and World War II, when public works departments (and later, the public employment programs of the New Deal) offered jobs of last resort for the down-on-their-luck or superannuated. RWA, which has reinvented much of the Wildcat Service Corporation, invites us to imagine a systematic attempt to recreate such "good bad jobs" (Campbell et al., this issue) on a large scale. Imbued with RWA's work and service ethic and combined with medical benefits and subsidized housing, such an employment program might provide for both material needs and the requisite social control of troubled and troublesome people. 
Given the accumulation of what appears to be a substantial middle-aged population with long-standing problems of addiction and unemployability, it seems to us that a federal block grant program could do a lot worse than to encourage widespread, carefully evaluated experimentation with the ADATSA and RWA models. Its admittedly ambitious goals would be to provide treatment and housing for all in need, work for those who are able to work, and adequate pensions for those who are unable to work.

Notes 1. Income maintenance programs in the United States are conventionally described as "insurance-like" when eligibility is related to a history of payroll deductions, or as "welfare" when basic eligibility is based on a person's level of income and assets. Federal disability benefits come as insurance (Social Security Disability Insurance) and as welfare (SSI). For more details, see Hunt and Baumohl (a, this issue) and Greenberg and Baumohl (1996).

2. The pensioning of disabled and aged people is only one form of public provision that can be manipulated this way. The much older mechanism of institutional care works similarly.

3. In market economies people may also provide for themselves legitimately by living on rents, interest, and other returns from investments, but this does not concern us here.

4. Hence the common practice of "workfare," a policy that at bottom preserves the principle of less eligibility by turning need-based assistance into low-wage work that is sometimes overtly punishing. This policy is reserved for categories of people whose estrangement from the labor force is regarded skeptically.

5. A few states supplement the federal minimum, but very modestly. If we consider the cash value of the federal SSI benefit to be what is known in social insurance parlance as a "wage replacement value," SSI provides less than two-thirds of the monthly value of the federal minimum wage, based on a 40-hour week. However, because those eligible for SSI automatically qualify for Medicaid in most states, this is misleading. Especially for those with substantial need for medical care, particularly prescription drugs, the combined package of SSI and Medicaid is arguably preferable to a minimum-wage job with no benefits. Indeed, over the last decade or so Congress has liberalized Social Security rules about allowable earned income in order to promote the vocational rehabilitation of SSI recipients afraid of losing their Medicaid once they forgo SSI. 
6. As Hunt and Baumohl ( $a, b$, this issue) note, all SSI beneficiaries are required to participate in treatment that might restore their capacity to work, but the DA\&A population is the only group ever subjected to the systematic enforcement of this rule.

7. 42 U.S.C. 12211 (1994). The correct term is "substance use disorder." This section of the Act puts "psychoactive substance abusers" in the company of homosexuals, bisexuals, transvestites, transsexuals, pedophiles, exhibitionists, voyeurs, compulsive gamblers, kleptomaniacs, and pyromaniacs, thus providing a roster of social types outside the boundary of even the most inclusive statutory definition of disability.

8. We confine our discussion to the basic contours of such a program. Hunt (2000) considers some of the technical issues in much greater detail and offers a different view of a potential federal role.

9. Scott and Baumohl's analysis of requalification for SSI benefits (this issue) suggests that while daily drinkers at baseline were significantly less likely to requalify than other DA\&A beneficiaries, selfreported substance use did not otherwise predict requalification. Speiglman, Norris et al. (this issue) find that self-reported substance use was greater among those who lost benefits. See Scott and Baumohl, their note 10 , for a discussion of this discrepancy.

10. The following discussion relies on website material from the Washington State Legislature (http: $\| w w w . l e g . w a . g o v / / R C W / / i n d e x)$ and interviews with Jim Friedman, a regional administrator of the Washington State Division of Alcohol and Substance Abuse (DASA), Ken Stark, director of DASA, and Doug Sevin, General Assistance program manager, Washington Department of Social and Health Services.

11. See Hunt and Baumohl ( $a$, this issue) for a detailed discussion of the SSI appeal process and the nature of retroactive benefits.

12. The following discussion of Ready, Willing \& Able is based on a process evaluation of the Philadelphia program that is winding up at this writing (January 2003). This is the work of the Temple University Center for Public Policy and the Bryn Mawr College Graduate School of Social Work and Social Research. Anne B. Shlay (Temple) and Jim Baumohl (Bryn Mawr) are the co-principal investigators.

13. In reality, the combined attrition rate in the Manhattan, Brooklyn, and Jersey City programs is quite high: In 2001, 49\% of all participants dropped out within 90 days. This figure was substantially higher for those under 30 years old and considerably lower for the relatively small number of participants in their fifties. Data for 1997-2001 show that a significant number of dropouts return to the program, however, and graduate at a fairly healthy rate (Rogers-Dillon, Unis, and Verba, 2002). 
References
Abramovitz, Mimi (1988). Regulating the Lives of Women: Social Welfare Policy from Colonial Times to the Present. Boston: South End Press.

Baumohl, Jim (1992a). Addiction and the American debate about homelessness. British Joumal of Addiction, 87: 7-10.

Baumohl, Jim (1992b). Hope needs work: Picking up from Hopper and Hawks. British Journal of Addiction, 87: 15-16.

Baumohl, Jim and Jerome Jaffe (2001). Treatment, history of, in the United States. In R.C. De Witt (ed.), Encyclopedia of Drigs, Alcohol, and Addictive Behavior (New York: Macmillan Publishing Company), 1116-1130.

Baumohl, Jim and Sarah W. Tracy (1994). Building systems to manage inebriates: The divergent paths of California and Massachusetts, 1891-1920. Contemporary Drug Problems, 21: 557-597.

Biernacki, Patrick (1986). Pathways from Heroin Addiction: Recovery Without Treatment. Philadelphia: Temple University Press.

Blumberg, Leonard U., Thomas F. Shipley, Jr., and Stephen F. Barsky (1978). Liquor and Poverty: Skid Row as a Human Condition. New Brunswick, NJ: Rutgers Center of Alcohol Studies.

California Institute for Mental Health (2000). The CalWORKs Project: The Prevalence of Mental Health, Alcohol and Other Drug, and Domestic Violence Issues among CalWORKs Participants in Kern and Stanislaus Counties (Sacramento, CA: Author).

Campbell, Kevin, Jim Baumohl, and Sharon R. Hunt (2003). The bottom line: Employment and barriers to work among former SSI drug addiction and alcoholism beneficiaries. Contemporary Drug Problems, 30: 195-240.

Catalano, R. and McConnell, W. (1999). Psychiatric emergencies: The check effect revisited. Joumal of Health and Social Behavior, 40: $79-86$.

Committee on Addictions of the Group for the Advancement of Psychiatry (2002). Responsibility and personal choice in addiction. Psychiatric Services, 53: 707-713.

Culhane, Dennis P., Stephen Metraux, and Trevor Hadley (2002). Public service reductions associated with placement of homeless persons with severe mental illness in supportive housing. Housing Policy Debate, 13: 107-163.

Currie, Elliott (1993). Reckoning: Drugs, the Cities, and the American Future. New York: Hill and Wang. 
Dasinger, Lisa, Richard Speiglman, and Jean Norris (December 2002). Alameda County CalWORKs Needs Assessment and Outcomes Study Report \# 5: The Relationship of Barriers, Supportive Services, Income, and Health Insurance with Work and Welfare over 27 Months. Berkeley, CA: Public Health Institute.

Davis, Martha F. (1993). Brutal Need: Lawyers and the Welfare Rights Movement, 1960-1973. New Haven, CT: Yale University Press.

Devine, Edward T. (1904). The Principles of Relief. New York: The Macmillan Company.

Edin, Kathryn and Laura Lein (1997). Making Ends Meet: How Single Mothers Survive Welfare and Low-Wage Work. New York: Russell Sage Foundation.

Elbogen, Eric B., Jeffrey W. Swanson, and Marvin S. Swartz (2002, April). Mandated community treatment and multiple forms of leverage in mental health services. Paper presented at NIMH Conference on Evidence in Mental Health Services Research. Washington, D.C.

Fleischer, Doris Zames and Frieda Zames (2001). The Disability Rights Movement: From Charity to Confrontation. Philadelphia: Temple University Press.

Gordon, Linda (1994). Pitied But Not Entitled: Single Mothers and the History of Welfare. New York: The Free Press.

Greenberg, Mark and Jim Baumohl (1996). Income maintenance: Little now, less on the way. In Jim Baumohl (ed.), Homelessness in America (Phoenix: Oryx Press), 63-77.

Guydish, Joseph, Claudia Ponath, Alan Bostrom, Kevin Campbell, and Nancy Barron (2003). Effects of losing SSI benefits on standard drug and alcohol outcome measures. Contemporary Drug Problems, 30: 169-193.

Hanrahan, Patricia, Daniel J. Luchins, Courtenay Savage, Gail Patrick, David Roberts, and Kendon J. Conrad (2002). Representative payee programs for persons with mental illness in Illinois. Psychiatric Services, 53: 190-194.

Harrison, L.H. (1997). The validity of self-reported drug use in survey research: An overview and critique of research methods. In L.H. Harrison and A. Hughes (eds.), The validity of self-reported drug use: Improving the accuracy of survey estimates. (DHHS Publication No. ADM 97-4147, pp. 17-36.) Washington, DC: U.S. Department of Health and Human Services. 
Hiller, M.L., K. Knight, K.M. Broome, and D.D. Simpson (1998). Legal pressure and treatment retention in a national sample of long-term residential programs. Criminal Justice and Behavior, 25: 463-481.

Hollister, Jr., Robinson G., Peter Kemper, and Rebecca A. Maynard (eds.) (1984). The National Supported Work Demonstration. Madison, WI: The University of Wisconsin Press.

Hopper, Kim (1992). On not leaving it to the feuilletons. British Joumal of Addiction, 87: 12-14.

Hopper, Kim and Jim Baumohl (1994). Held in abeyance: Rethinking homelessness and advocacy. American Behavioral Scientist, 37: 522552.

Hunt, Sharon R. (2000). Drug addiction and alcoholism as qualifying impaiments for Social Security benefits: The history, controversies, and congressional response. Ph.D. dissertation, Brandeis University, Waltham, MA.

Hunt, Sharon R. and Jim Baumohl (2003a). Drink, drugs, and disability: An introduction to the controversy. Contemporary Drug Problems, 30: $9-76$.

Hunt, Sharon R. and Jim Baumohl (2003b). Now invited to testify: Former beneficiaries appraise the SSI drug addiction and alcoholism program. Contemporary Drug Problems, 30: 455-499.

Lender, Mark Edward and James Kirby Martin (1987, revised and expanded). Drinking in America: A History. New York: The Free Press.

Levine, Harry Gene (1978). The discovery of addiction: Changing conceptions of habitual drunkenness in American history. Journal of Studies on Alcohol, 39: 143-174.

Loprest, Pamela (1999). Families Who Left Welfare and How They Are Doing. Washington, DC: Urban Institute.

Manpower Demonstration and Research Corporation (MDRC) (1980). Summary and Findings of the National Supported Work Demonstration. Cambridge, MA: Ballinger Publishing Co.

McLellan, Thomas A., David Lewis, Charles P. O’Brien, and Herbert Kleber (2000). Drug dependence, a chronic medical illness: Implications for treatment, insurance, and outcomes evaluation. Journal of the American Medical Association, 284(13): 1689-1695.

National Low Income Housing Coalition (2002). Rental Housing for America's Poor Families: Farther Out of Reach Than Ever. http://www.nlihc.org/oor2002/. 
Norris, Jean, Richard Scott, Richard Speiglman, and Rex Green (2003). Homelessness, hunger and material hardship among those who lost SSI. Contemporary Drug Problem, 30: 241-273.

Norris, Jean, Richard Speiglman, and Lisa Dasinger (2002). San Joaquin County CalWORKs Needs Assessment and Outcomes Study Report \# 1: Health and Other Potential Barriers to Working and Self-Sufficiency. Berkeley, CA: Public Health Institute.

Orwick, Beth Hensley (2001). "Bartender, I'll have a beer and a disability"; alcoholism and the Americans with Disabilities Act: Affirming the importance of the individualized inquiry in determining the definition of disability. St. Louis University Public Law Review, 20: 195222.

Pollack, Harold A., Sheldon Danziger, Kristin S. Seefeldt, and Rukmalie Jayakody (2002). Substance use among welfare recipients: Trends and policy responses. Social Service Review, 76: 256-274.

Rank, Mark Robert (1994). Living on the Edge: The Realities of Welfare in America. New York: Columbia University Press.

Ringenbach, Paul T. (1973). Tramps and Reformers, 1873-1916: The Discovery of Unemployment in New York. Westport, CT: Greenwood Press.

Rogers-Dillon, Robin, Sharon Unis, and Michael Verba (August 30, 2002). Reducing homelessness and criminal recidivism: Caseload dynamics of the Ready, Willing \& Able program \& ComALERT programs (unpublished report).

Roizen, Ron (1987). The great controlled-drinking controversy. In Marc Galanter (ed.), Recent Developments in Alcoholism, Volume 5 (New York: Plenum Press), 245-279.

Rosen, Marc I., Robert A. Rosenheck, Andrew L. Shaner, Thad A. Eckman, Gail Gamache, and Christopher Krebs (2002). Substance abuse and the need for money management assistance among psychiatric inpatients. Drug and Alcohol Dependence, 67: 331-334.

Rosenheck, Robert and Linda K. Frisman (1996). Do public support payments encourage substance abuse? Health Affairs, 15: 192-200.

Rosenheck, Robert, Julie Lam, and Frances Randolph (1997). Impact of representative payees on substance use by homeless persons with serious mental illness. Psychiatric Services, 48: 800-806.

Schram, Sanford F. and Joe Soss (2001). Success stories: Welfare reform, policy discourse, and the politics of research. The Annals, No. 577 (September 2001): 49-65. 
Scott, Richard and Jim Baumohl (2003). Decisions to appeal, decisions to approve: Requalification for SSI by former DA\&A beneficiaries. Contemporary Drug Problems, 30: 147-168.

Shaner, Andrew, Thad Eckman, Lisa J. Roberts, Jeffrey N. Wilkins, Douglas E. Tucker, John W. Tsuang, and Jim Mintz (1995, September 21). Disability income, cocaine use, and repeated hospitalization among schizophrenic cocaine abusers-government sponsored revolving door. New England Journal of Medicine, 333: 777-783.

Shaner, A., L.J. Roberts, T.A. Eckman, D.E. Tucker, J.W. Tsuang, J.N. Wilkins, and J. Mintz (1997). Monetary reinforcement of abstinence from cocaine among mentally ill patients with cocaine dependence. Psychiatric Services, 48: 807-814.

Simpson, D.D., G.W. Joe, and K.M. Broome (2002). A national 5-year follow-up of treatment outcomes for cocaine dependence. Archives of General Psychiatry, 59: 538-544.

Skidmore, Felicity (1984). The impacts of supported work on former drug addicts. In Robinson G. Hollister, Jr., Peter Kemper, and Rebecca A. Maynard (eds.), The National Supported Work Demonstration (Madison, WI: The University of Wisconsin Press), 136-171.

Sobell, L.C., T.P. Ellingstad, and M.B. Sobell (2000). Natural recovery from alcohol and drug problems: Methodological review of the research with suggestions for future directions. Addiction, 95: 749764.

Sobell, M.B and L.C. Sobell (1995). Controlled drinking after 25 years: How important was the debate? Addiction, 90: 1149-1153.

Speiglman, Richard, Jean Norris, Shanthi Kappagoda, Rex Green, and Zoran Martinovich (2003). SSI receipt and alcohol and other drug use among former SSI DA\&A beneficiaries. Contemporary Drug Problems, 30: 291-333.

Stone, Deborah (1984). The Disabled State. Philadelphia: Temple University Press.

Swartz, James A., Kevin Campbell, Jim Baumohl, and Peggy Tonkin (2003). Drug treatment participation and retention rates among former recipients of Supplemental Security Income for drug addiction and alcoholism. Contemporary Drug Problems, 30: 335-364.

Swartz, James A., Chang-ming Hsieh, and Jim Baumohl (in press). Disability benefits, drug use, and representative payment: An analysis of the relationships. Addiction. 
Swartz, James A. and Zoran Martinovich (2003). General course and correlates of improvement and decline following termination of the Supplemental Security Income category for drug addiction and alcoholism. Contemporary Drug Problems, 30: 425-454.

Swartz, James A., Zoran Martinovich, and Paul Goldstein (2003). An analysis of the criminogenic effects of terminating the Supplemental Security Income impairment category for drug addiction and alcoholism. Contemporary Drug Problems, 30: 391-424.

Swartz, James A., Peggy Tonkin, and Jim Baumohl (2003). The methodology of the multi-site study of the termination of Supplemental Security Income benefits for drug addicts and alcoholics. Contemporary Drug Problems, 30: 77-121.

U.S. House of Representatives, Committee on Ways and Means, Exploring Means of Achieving Higher Rates of Treatment and Rehabilitation Among Alcoholics and Drug Addicts Receiving Federal Disability Benefits, February 10, 1994 (Washington, DC: U.S. Government Printing Office, 1994), Serial 103-75.

Waldorf, Dan, Craig Reinarman, and Sheigla Murphy (1991). Cocaine Changes: The Experience of Using and Quitting. Philadelphia: Temple University Press.

Weir, Margaret (1992). Politics and Jobs. Princeton, NJ: Princeton University Press.

White, William L. (1998). Slaying the Dragon: The History of Addiction Treatment and Recovery in America. Bloomington, IL: Chestnut Health Systems/Lighthouse Institute.

Wiseman, Jacqueline P. (1971). Stations of the Lost: The Treatment of Skid Row Alcoholics. Englewood Cliffs, NJ: Prentice-Hall.

Young, Nancy K. (2000). Integrating Substance Abuse Treatment and Vocational Services. Treatment Improvement Protocol (TIP) Series 38. Rockville, MD: U.S. Department of Health and Human Services, Public Health Service, Substance Abuse and Mental Health Services Administration, Center for Substance Abuse Treatment. 